\title{
Integrated bioinformatics analysis of potential pathway biomarkers using abnormal proteins in clubfoot
}

\author{
Guiquan Cai ${ }^{1}$, Xuan Yang ${ }^{2}$, Ting Chen ${ }^{2}$, Fangchun Jin ${ }^{2}$, Jing Ding ${ }^{\text {Corresp., } 2}$, Zhenkai Wu ${ }^{\text {Corresp. } 2}$ \\ ${ }^{1}$ Department of Orthopaedics, Xinhua Hospital, School of Medicine, Shanghai Jiao Tong University, Shanghai, China \\ 2 Department of Pediatric Orthopaedics, Xinhua Hospital, School of Medicine, Shanghai Jiao Tong University, Shanghai, China \\ Corresponding Authors: Jing Ding, Zhenkai Wu \\ Email address: dingjing@xinhuamed.com.cn, wuzhenkai@xinhuamed.com.cn
}

Background: As one of the most common major congenital distal skeletal abnormalities, congenital talipes equinovarus (clubfoot) affects approximately one in one thousandth newborns. Although several etiologies of clubfoot have been proposed and several genes have been identified as susceptible genes, previous studies did not further explore signaling pathways and potential upstream and downstream regulatory networks. Therefore, the aim of the present investigation is to explore abnormal pathways and their interactions in clubfoot using integrated bioinformatics analyses. Methods: KEGG, gene ontology (GO), Reactome (REAC), WikiPathways (WP) or human phenotype ontology (HP) enrichment analysis were performed using WebGestalt, g:Profiler and NetworkAnalyst. Results: A large number of signaling pathways were enriched e.g. signal transduction, disease, metabolism, gene expression (transcription), immune system, developmental biology, cell cycle, and ECM. Protein-protein interactions (PPIs) and gene regulatory networks (GRNs) analysis results indicated that extensive and complex interactions occur in these proteins, enrichment pathways, and TF-miRNA coregulatory networks.

Transcription factors such as SOX9, CTNNB1, GLI3, FHL2, TGFBI and HOXD13, regulated these candidate proteins. Conclusion: The results of the present study supported previously proposed hypotheses, such as ECM, genetic, muscle, neurological, skeletal, and vascular abnormalities. More importantly, the enrichment results also indicated cellular or immune responses to external stimuli, and abnormal molecular transport or metabolism may be new potential etiological mechanisms of clubfoot. 
2 Integrated bioinformatics analysis of potential pathway biomarkers using abnormal proteins in clubfoot

4

5 Guiquan Cai ${ }^{1, \#}$, Xuan Yang ${ }^{2, \#}$, Ting Chen², Fangchun Jin², Jing Ding ${ }^{2, *}$, Zhenkai Wu ${ }^{2, *}$

7 1. Department of Orthopaedics, Xinhua Hospital, School of Medicine, Shanghai Jiao Tong 8 University, Shanghai 200092, China.

9 2. Department of Pediatric Orthopaedics, Xinhua Hospital, School of Medicine, Shanghai Jiao 10 Tong University, Shanghai 200092, China.

12 \# These two authors contributed equally and share first author.

13 * Correspondence to: Dr. Jing Ding, Department of Pediatric Orthopaedics, Xinhua Hospital, 14 School of Medicine, Shanghai Jiao Tong University, No. 1665, Kongjiang Road, Shanghai 15 200092, China. E-mail: dingjing@xinhuamed.com.cn. Dr. Zhenkai Wu, Department of Pediatric Orthopaedics, Xinhua Hospital, School of Medicine, Shanghai Jiao Tong University, No. 1665, Kongjiang Road, Shanghai 200092, China. E-mail: wuzhenkai@xinhuamed.com.cn.

Short Title: Potential pathway biomarkers in clubfoot 
22 ABSTRACT

23 Background: As one of the most common major congenital distal skeletal abnormalities, congenital talipes equinovarus (clubfoot) affects approximately one in one thousandth newborns.

Although several etiologies of clubfoot have been proposed and several genes have been identified as susceptible genes, previous studies did not further explore signaling pathways and potential upstream and downstream regulatory networks. Therefore, the aim of the present investigation is to explore abnormal pathways and their interactions in clubfoot using integrated bioinformatics analyses.

Methods: KEGG, gene ontology (GO), Reactome (REAC), WikiPathways (WP) or human phenotype ontology (HP) enrichment analysis were performed using WebGestalt, g:Profiler and NetworkAnalyst.

Results: A large number of signaling pathways were enriched e.g. signal transduction, disease, metabolism, gene expression (transcription), immune system, developmental biology, cell cycle, and ECM. Protein-protein interactions (PPIs) and gene regulatory networks (GRNs) analysis results indicated that extensive and complex interactions occur in these proteins, enrichment pathways, and TF-miRNA coregulatory networks. Transcription factors such as SOX9, CTNNB1, GLI3, FHL2, TGFBI and HOXD13, regulated these candidate proteins. Conclusion: The results of the present study supported previously proposed hypotheses, such as ECM, genetic, muscle, neurological, skeletal, and vascular abnormalities. More importantly, the enrichment results also indicated cellular or immune responses to external stimuli, and abnormal molecular transport or metabolism may be new potential etiological mechanisms of clubfoot. 


\section{Keywords:}

45 Congenital talipes equinovarus; Clubfoot; Etiological mechanisms; Bioinformatics analysis;

46 Enrichment analysis

47 


\section{INTRODUCTION}

49 As a common developmental malformation of newborns, clubfoot affects approximately $2 \%$ of newborns (Wang et al., 2019). If not actively and timely treated, this deformity will accompany the child for a lifetime, which will not only affect the appearance of the child, including walking difficulties or even a disability, but also cause serious adverse effects on the mental health of the child. Therefore, timely and active treatments are urgently needed. The treatment of clubfoot includes surgical and nonsurgical treatments. Surgical releases, such as muscle balance and anterior tibial tendon transposition, may cause many problems, such as large trauma complications, which seriously affect the healthy development of children (Smith et al., 2014). The number of extensive surgical cases of clubfoot has declined by $60 \%$ from 1996 to 2006 in the United States (Zionts et al., 2010). In contrast, the Ponseti method has received increasing attention in the treatment of clubfoot and has become the most commonly used method. Although the success rate of Ponseti's first correction is satisfactory after a long period of development, there are still many problems and challenges, such as having a recurrence of (Miller et al., 2016; Thacker et al., 2005). soft tissue contracture, vascular abnormalities, ECM abnormalities, and intrauterine growth retardation (Chesney et al., 2007; Eckhardt et al., 2019; Miedzybrodzka 2003; Ošt'ádal et al., 2015; Poon and Li, 2009; Sodre et al., 1990; Wang et al., 2013). In addition, smoking and viral 
69

infections in pregnant women are also closely related to congenital clubfoot (Palma et al., 2013;

Robertson and Corbett, 1997). Although the direct cause of congenital clubfoot remains to be

unified, these findings provide an important opportunity and basis for the treatments of clubfoot.

Several studies have revealed that botulinum toxin injection can relieve muscle or soft tissue contracture and may replace percutaneous tendoachilles tenotomy in the treatment of clubfoot (Alvarez et al., 2009; Howren et al., 2015). Based on the progress of pathogenesis, appropriate drug treatment may improve patient compliance and ultimately improve the efficacy of the Ponseti method. In addition, familial occurrence and inter- and intraphenotypic variability of clubfoot is well documented (Basit and Khoshhal, 2018). Several genes were identified as susceptible genes in clubfoot, such as the HOX family, CASP family, PITX-TXB4 pathway, troponin (TN) family, GLI3, T-box and MTHFR genes (Hecht et al. 2007; Shrimpton et al., 2004; Shyy et al., 2009; Weymouth et al., 2016; Zhang Z et al., 2016). However, these studies do not further explore abnormally active signaling pathways and potential upstream and downstream regulatory networks. Therefore, the aim of the present investigation is to explore the abnormal pathways and their interactions using integrated bioinformatics analysis in clubfoot. We expect the results of this study will provide an update on the etiopathogenetic mechanism of idiopathic clubfoot.

MATERIALS AND METHODS

Inclusion of abnormal proteins 
90 Two widely used databases, PubMed and Science Direct, were used for literature retrieval.

91 Keywords were "(clubfoot or clubfeet or congenital talipes equinovarus) and (etiology or

92

embryology or etiopathogenesis or genomics or genetics or pathology or pathophysiology)". The search date was up to May 7, 2019. A total of 1057 articles were found in PubMed, and 657 articles were found in Science Direct. After eliminating duplicate articles, a total of 1093 studies were retrieved. By reading the title and abstract, 1015 articles were eliminated following the inclusion and exclusion criteria as described below. Inclusion criteria included clinical or preclinical studies written in English that were focused on the etiology of clubfeet. Investigations with a focus on secondary/syndromic clubfoot, such as distal arthrogryposis, myelomeningocele, and moebius syndrome, were excluded. We performed a full text assessment of the remaining 78 articles. A total of 47 articles were excluded because the study topic was not clubfoot, genetic information was not mentioned or full text of the study was not available. Finally, 8 articles were included in the present study. A total of 30 proteins that are shown in table 1 were used in this investigation after assessing the protein. The process of the inclusion of abnormal proteins was shown in Figure 1. 
Table 1. Protein information.

\begin{tabular}{|c|c|c|c|c|}
\hline Entry ID & Entry name & Protein names & Gene names & References \\
\hline Q9BXN1 & ASPN_HUMAN & Asporin & ASPN & $\begin{array}{l}\text { Ošt'ádal et al. } \\
2015\end{array}$ \\
\hline P21810 & PGS1_HUMAN & Biglycan & BGN & $\begin{array}{l}\text { Ošttádal et al. } \\
2015\end{array}$ \\
\hline Q8IUL8 & CILP2_HUMAN & $\begin{array}{l}\text { Cartilage intermediate } \\
\text { layer protein } 2, \text { CILP- } \\
2\end{array}$ & CILP2 & $\begin{array}{l}\text { Eckhardt et al. } \\
2019\end{array}$ \\
\hline P35222 & CTNB1_HUMAN & $\begin{array}{l}\text { Catenin beta-1 (Beta- } \\
\text { catenin) }\end{array}$ & CTNNB1 & Poon et al. 2009 \\
\hline P02461 & CO3A1_HUMAN & $\begin{array}{l}\text { Collagen alpha-1(III) } \\
\text { chain }\end{array}$ & COL3A1 & $\begin{array}{l}\text { Eckhardt et al. } \\
2019\end{array}$ \\
\hline P20908 & CO5A1_HUMAN & $\begin{array}{l}\text { Collagen alpha-1(V) } \\
\text { chain }\end{array}$ & COL5A1 & $\begin{array}{l}\text { Eckhardt et al. } \\
2019\end{array}$ \\
\hline P12109 & CO6A1_HUMAN & $\begin{array}{l}\text { Collagen alpha-1(VI) } \\
\text { chain }\end{array}$ & COL6A1 & $\begin{array}{l}\text { Eckhardt et al. } \\
2019\end{array}$ \\
\hline Q99715 & COCA1_HUMAN & $\begin{array}{l}\text { Collagen alpha-1(XII) } \\
\text { chain }\end{array}$ & COL12A1 & $\begin{array}{l}\text { Eckhardt et al. } \\
2019\end{array}$ \\
\hline Q05707 & COEA1_HUMAN & $\begin{array}{l}\text { Collagen alpha- } \\
1 \text { (XIV) chain } \\
\text { (Undulin) }\end{array}$ & COL14A1 & $\begin{array}{l}\text { Eckhardt et al. } \\
2019\end{array}$ \\
\hline P08123 & CO1A2_HUMAN & $\begin{array}{l}\text { Collagen alpha-2(I) } \\
\text { chain }\end{array}$ & COL1A2 & $\begin{array}{l}\text { Eckhardt et al. } \\
2019\end{array}$ \\
\hline P12110 & CO6A2_HUMAN & $\begin{array}{l}\text { Collagen alpha-2(VI) } \\
\text { chain }\end{array}$ & COL6A2 & $\begin{array}{l}\text { Eckhardt et al. } \\
2019\end{array}$ \\
\hline P12111 & CO6A3_HUMAN & $\begin{array}{l}\text { Collagen alpha-3(VI) } \\
\text { chain }\end{array}$ & COL6A3 & $\begin{array}{l}\text { Eckhardt et al. } \\
2019\end{array}$ \\
\hline$\underline{\mathrm{P} 20849}$ & CO9A1_HUMAN & $\begin{array}{l}\text { Collagen alpha-1(IX) } \\
\text { chain }\end{array}$ & COL9A1 & Wang et al. 2013 \\
\hline O94907 & DKK1_HUMAN & $\begin{array}{l}\text { Dickkopf-related } \\
\text { protein 1, Dickkopf-1 }\end{array}$ & DKK1 & Poon et al. 2009 \\
\hline Q06828 & FMOD_HUMAN & Fibromodulin & FMOD & $\begin{array}{l}\text { Eckhardt et al. } \\
2019 \text {, }\end{array}$ \\
\hline P02751 & FINC_HUMAN & $\begin{array}{l}\text { Fibronectin (Cold- } \\
\text { insoluble globulin, } \\
\text { CIG) }\end{array}$ & FN1 & $\begin{array}{l}\text { Ošt'ádal et al. } \\
2015\end{array}$ \\
\hline Q14192 & FHL2_HUMAN & $\begin{array}{l}\text { Four and a half LIM } \\
\text { domains protein }\end{array}$ & FHL2 & Wang et al. 2008 \\
\hline P35453 & HXD13_HUMAN & Homeobox protein & HOXD13 & Wang et al. 2008 \\
\hline
\end{tabular}




\begin{tabular}{|c|c|c|c|c|}
\hline & & $\begin{array}{l}\text { Hox-D13 (Homeobox } \\
\text { protein Hox-4I) }\end{array}$ & & \\
\hline P51884 & LUM_HUMAN & Lumican & LUM & $\begin{array}{l}\text { Ošttádal et al. } \\
2015\end{array}$ \\
\hline Q16853 & AOC3_HUMAN & $\begin{array}{l}\text { Membrane primary } \\
\text { amine oxidase }\end{array}$ & $\mathrm{AOC} 3$ & $\begin{array}{l}\text { Ošt'ádal et al. } \\
2015\end{array}$ \\
\hline P20774 & MIME_HUMAN & $\begin{array}{l}\text { Mimecan } \\
\text { (Osteoglycin) }\end{array}$ & OGN & $\begin{array}{l}\text { Ošt'ádal et al. } \\
2015\end{array}$ \\
\hline Q15063 & POSTN_HUMAN & $\begin{array}{l}\text { Periostin (Osteoblast- } \\
\text { specific factor 2) }\end{array}$ & POSTN & $\begin{array}{l}\text { Ošt'ádal et al. } \\
2015\end{array}$ \\
\hline P51888 & PRELP_HUMAN & Prolargin & PRELP & $\begin{array}{l}\text { Ošt'ádal et al. } \\
2015\end{array}$ \\
\hline Q7Z7G0 & TARSH_HUMAN & Target of Nesh-SH3 & ABI3BP & $\begin{array}{l}\text { Ošt'ádal et al. } \\
2015\end{array}$ \\
\hline P24821 & TENA_HUMAN & $\begin{array}{l}\text { Tenascin, TN } \\
\text { (Cytotactin) }\end{array}$ & $\mathrm{TNC}$ & $\begin{array}{l}\text { Eckhardt et al. } \\
\text { 2019, Ošt'ádal et } \\
\text { al. } 2015\end{array}$ \\
\hline Q15582 & BGH3_HUMAN & $\begin{array}{l}\text { TGF- } \beta \text {-induced } \\
\text { protein ig-h3 }\end{array}$ & TGFBI & $\begin{array}{l}\text { Eckhardt et al. } \\
2019\end{array}$ \\
\hline P48436 & SOX9_HUMAN & $\begin{array}{l}\text { Transcription factor } \\
\text { SOX-9 }\end{array}$ & SOX9 & Wang et al. 2013 \\
\hline P10071 & GLI3_HUMAN & $\begin{array}{l}\text { Transcriptional } \\
\text { activator GLI3 }\end{array}$ & GLI3 & Cao et al. 2009 \\
\hline P01137 & TGFB1_HUMAN & TGF- $\beta-1$ proprotein & TGFB1 & Wang et al. 2013 \\
\hline P13611 & CSPG2_HUMAN & Versican core protein & VCAN & $\begin{array}{l}\text { Eckhardt et al. } \\
\text { 2019, Ošt'ádal et } \\
\text { al. } 2015\end{array}$ \\
\hline
\end{tabular}

\section{WebGestalt analysis}

109 WebGestalt analysis was performed as described previously (Wang et al., 2017). The parameters

110 for the enrichment analysis were as follows. A specific organism was chosen $H$. sapiens (human).

111 Enrichment categories were used KEGG, Panther and Reactome pathways. A reference list was

112 used for all mapped entrezgene IDs from the selected platform genome. The reference list was

113 mapped to 61506 entrezgene IDs, and 2266 IDs were annotated to the selected functional 
114 115 116 117 118 119 120

categories and used as the reference for the enrichment analysis. The minimum number of IDs in each category was 5, and the maximum number of IDs was 2000. Among 30 unique entrezgene IDs, 19 IDs were annotated to the selected functional categories and used for the enrichment analysis. The Gene Ontology (GO) Slim summary was based upon 30 unique entrezgene IDs. Fisher's exact test-based overpresentation enrichment analysis (ORA) method was used for enrichment analysis. FDR was used for the Benjamani-Hochberg $(\mathrm{BH})$ method.

\section{g:Profiler analysis}

The version of g:Profiler was e94_eg41_p11_9f195a1 (database updated on 01/24/2019). The parameters for the enrichment analysis were as follows. A specific organism was chosen $H$. sapiens (human). GO analyses (GO molecular function (GO: MF), GO cellular component (GO:

$\mathrm{CC}$ ), and GO biological process (GO: BP)) were carried out sequentially. The biological pathways used were the KEGG, Reactome, and WikiPathways databases. The protein databases used were the Human Protein Atlas and CORUM databases. The statistical domain scope was used only for annotated genes. The significance threshold was the g:SCS threshold. The user threshold was 0.05 .

\section{NetworkAnalyst analysis}

The significantly changed genes from the previous analyses were mapped to the corresponding molecular interaction databases. The procedure typically produces one large subnetwork with several smaller ones. The website was upgraded and maintained until May 8, 2019 by the Xia 
135

136

137

138

139

140

141

142

143

144

145

146

147

148

149

150

151

152

153

154

155

7

Lab (https://www.networkanalyst.ca/NetworkAnalyst/faces/home.xhtml). The parameters for the enrichment analysis were as follows. A specific organism was chosen H. sapiens (human). The

ID type was chosen Uniprot Protein ID. PPI analysis was performed using the MEx Interactome database. The parameters were referred to the literature-curated comprehensive data from the Innate DB (Breuer et al., 2013). Gene-miRNA interactome analysis was carried out with comprehensive experimentally validated miRNA-gene interaction data collected from TarBase and miRTarBase (Chou et al., 2018; Vlachos et al., 2015). TF-gene interaction analysis was performed using the ENCODE database. Transcription factor and gene target data derived from the ENCODE ChIP-seq data. The peak intensity signal $<500$ and the predicted regulatory potential score $<1$ used the BETA Minus algorithm (Wang et al., 2013). TF-miRNA coregulatory network analysis was performed using curated regulatory interaction information collected from the RegNetwork repository (Liu et al., 2015).

\section{REAC enrichment analysis}

The enrichment analysis was performed against Reactome version 66 on 04/05/2019 using UniProt identifiers for the mapping. The web link is as follows:

https://reactome.org/PathwayBrowser. Information in the REAC database is authored by expert biologists and entered and maintained by Reactome's team of curators and editorial staff.

Reactome content frequently cross-references other resources, e.g., NCBI, Ensembl, UniProt, KEGG (Gene and Compound), ChEBI, PubMed and GO. REAC analysis was performed as described previously (Fabregat et al., 2016). The parameters for the enrichment analysis were as 
156 follows. A specific organism was chosen H. sapiens (human). IntAct interactors were included to

157 increase the analysis background. An overrepresentation analysis method was used for

158 enrichment analysis. This test produces a probability score, which was corrected for the false

159 discovery rate using the $\mathrm{BH}$ method. Twenty-seven out of 30 identifiers in the sample were

160 found in Reactome, and 430 pathways were found by at least one of the identifiers.

\section{Statistics}

The enrichment analysis method in the WebGestalt analysis was used for ORA method. The significance threshold in the g:Profiler analysis was the g:SCS threshold (g:Profiler analysis soft version: e94_eg41_p11_9f195a1 (database updated on 01/24/2019)). The adjusted p value method used was the $\mathrm{BH}$ method and the adjusted $\mathrm{p}$ value was transformed to negative $\log 10$ ($\log 10($ AdjP)). All significantly changed pathways and interactions had a $\mathrm{p}$ value $<0.05$.

\section{RESULTS}

\section{Results of the enrichment analysis by g:Profiler and Reactome}

To visually observe the enrichment information of these candidate proteins, g: Profiler and

Reactome were performed for the bioinformatics analysis. A large number of terms were number of signaling pathways were enriched by Reactome (Figure 2B). Additionally, there were extensive interactions among these signaling pathways (Figure 2B). 
177 To clarify the categories of these pathways, we summarized these pathways enriched by REAC.

178 Signal transduction, disease, metabolism, gene expression (transcription), and immune system

179 were the top 5 pathways and their percentages were as high as $65 \%$ (Figure $3 \mathrm{~A}$ ). Among the 30

180 proteins, the top 10 proteins with the widest participation, such as P35222, P01137, P02751 and

181 P08123, were mainly ECM proteins or proteins that interact with the ECM (Figure 3B, 3C). We

182 continued to summarize the top 10 pathways and found that these pathways were mainly focused

183 on the ECM, metabolism and cell communication (Figure 3D).

\section{Results of the signaling pathway enrichment analysis}

Through the Reactome enrichment analysis, a large number of pathways were enriched (Figure

2/3). To further analyze these potential pathways, signaling pathway enrichment analysis was

carried out using g:Profiler in the REAC, WP, KEGG and HP. A total of 32, 11, 7 and 30

pathways were enriched by g:Profiler, respectively (Figure 4A-4D). Classification analysis

revealed that these pathways were mainly concentrated in ECM, disease and metabolic pathways

(Figure 4E). The proportion of the top three was as high as $78 \%$. In addition, human phenotype

ontology enrichment analysis results revealed that these abnormal proteins were mainly

expressed in the lower appendages, such as muscle, ankle, foot, joint, skin and connective tissue,

and their proportion was more than 50\% (Figure 4F). Similar, similar results were found in

KEGG and REAC enrichment analyses using NetworkAnalyst and WebGestalt (Figure S1).

\section{Results of the GO enrichment analysis}


198

199

200

201

202

203

204

205

206

207

208

209

210

211

212

213

214

215

216

217

GO enrichment analysis was further performed to explore the BP, MF and CC induced by these

proteins. A total of 69, 9 and $24 \mathrm{GO}$ terms were enriched by g:Profiler in BP, MF and CC,

respectively (Figure 5A-5C). Classification analysis revealed that GO: BP was mainly

concentrated in embryo or organ development, and its combined percentage was over $80 \%$

(Figure 5E). Among these pathways, skeletal development was dominant. ECM function, growth

factor binding, cell adhesion, heparin binding and protein binding were the main pathways in MF,

and their percentages were as high as $85 \%$ (Figure 5F). Additionally, ECM and membrane were

the main $\mathrm{CC}$, and their percentages were almost $60 \%$ (Figure $5 \mathrm{G}$ ). In addition, GO enrichment

analysis results analyzed by NetworkAnalyst were consistent with those from g:Profiler (Figure

S2).

\section{Results of PPIs and gene regulatory networks analysis}

The NetworkAnalyst analysis was performed to explore protein-protein interactions and gene

regulatory networks for genes that code these candidate proteins. These genes interact

extensively with predictive genes (Figure 6A). A total of 2630 PPIs were enriched by

NetworkAnalyst. There are 1263 interactions that were related to the top 10 genes and these

interactions account for $48 \%$ of the total. The top genes were FN1, CTNNB1, FHL2, TGFB1 and

COL1A2 (Figure 6B). Among these genes, FN1 and CTNNB1 were dominant, and the

percentage of PPIs induced by these two genes was almost $39 \%$.

TF-gene interactions were also enriched by NetworkAnalyst. A total of 692 TF-gene interactions 
219 were enriched (Figure 6C). The top genes were TGFB1, FN1, SOX9, AOC3 and HOXD13

220 (Figure 6D). Additionally, the interactions among these 10 genes were as high as $43 \%$ of the

221 total.

222

223 Gene-miRNA interactome analysis results revealed that 409 interactomes were identified

224 between these genes and predictive miRNAs (Figure 6E). The top genes were FHL2, PRELP,

225 CTNNB1, SOX9 and COL12A1 (Figure 6F). Top miRNAs were hsa-mir-124-3p, hsa-mir-26b-

$2265 \mathrm{p}$, hsa-mir-335-5p, hsa-mir-1-3p and hsa-mir-5698. The interactomes between the top 10 genes

227 and the top 10 miRNAs accounted for $39 \%$ and $5 \%$ of the total, respectively.

228

229 A large number of TF-miRNA coregulatory interactions were enriched (Figure 6G).

230 Transcription factors, such as SOX9, CTNNB1, GLI3, FHL2, TGFBI and HOXD13, cooperated

231 with hsa-miR-29a, hsa-miR-101, hsa-miR-520d-5p, hsa-miR-29b and hsa-miR-568 to regulate

232 these candidate genes (Figure 6G). The top 10 genes were SOX9, CTNNB1, GLI3, FHL2,

233 TGFB1, TGFBI, VCAN, TNC, COL12A1 and COL5A1 (Figure 6H).

234

235 Combining the four interactions mentioned above, 19 genes were involved in the top interactions

236 (Figure 6I). SOX9, CCNNB1, VCAN, TGFB1, FHL2 and COL12A1 widely participated in the

top-ranking interactions (Figure $6 \mathrm{~J}$ ).

\section{DISCUSSION}


240 In the present investigation, a large number of signaling pathways were enriched in the GO,

241 KEGG, REAC, WP and HP databases using g:Profiler, NetworkAnalyst and WebGestalt

242 analyses of clubfoot. Among them, pathways in embryo or organ development, ECM,

243 metabolism, immune system, cell cycle, cell responses to external stimuli, and apoptosis or

244 programmed cell death were the top pathways. A wide range of interactions existed among these

245 enriched signaling pathways. In addition, there were also extensive regulations between the upstream and downstream of genes encoding these proteins.

There were 452 enriched pathways identified by REAC enrichment analysis. Among them, signal transduction, disease, metabolism, gene expression (transcription), immune system, developmental biology, cell cycle, ECM and hemostasis were advantageous pathways.

Additionally, signaling pathways in DNA repair, PCD, cell response to external stimuli, cell-cell communication, molecular transport and chromatin organization were enriched. In the process of cell biological activities, numerous changes occurred in cells, such as signal transduction, gene expression, cell cycle, DNA repair, molecular transport and metabolism. Abnormal changes in these biological processes may alter cell fate, cell-cell communication, and cell response to external stimuli or even cause immune system changes.

Select soft tissues in clubfoot are contracted, resulting in stiffness. Extracellular matrix proteins, such as asporin, collagen types III, V, and VI, versican, tenascin-C, and TGF-beta induced protein, are highly expressed in contracted tissues clubfoot (Eckhardt et al., 2019; Ošt'ádal et al., 
261

262

263

264

265

266

267

268

269

270

271

272

273

274

275

276

277

278

279

280

2015). Additionally, the expression levels of growth factors TGF-beta and platelet-derived

growth factor are high and a blockade of growth factors led to decreased collagen expression,

proliferation, and chemotaxis ( $\mathrm{Li}$ et al., 2001). These proteins seem to be promising targets for

future investigations and treatments of this disease. Indeed, the muscle contraction strategy, such

as botulinum toxin injection, can relieve muscle or soft tissue contracture and thus improve and

alleviate clubfoot symptoms (Howren et al., 2015; Shrimpton et al., 2004). ECM-associated

pathways were enriched and included collagen chain trimerization, collagen formation and

degradation, and ECM proteoglycans. TGF-beta receptor signaling was also enriched. These

findings support the idea that these ECM proteins are promising targets for the treatment of

clubfoot.

Abnormal biological development, such as muscle, neurological, skeletal and vascular

abnormalities, has been previously identified and confirmed (Basit and Khoshhal, 2018;

Eckhardt et al., 2019; Herceg et al., 2006; Hester et al., 2009; Lovell et al., 2007; Ošt'ádal et al., 2015). The HOX and TBX families governed limb identity, and fibroblast growth factor

participated in the formation of limb muscles (Ohuchi and Noji, 1999; Wang et al., 2008).

Additionally, gene-gene interactions between CASP SNPS and variants in HOXA, HOXD, and

insulin-like growth factor binding protein affect muscle and limb development (Ester et al.,

2010). Apoptosis and programmed cell death associated pathways and activation of HOX gene

pathways, such as activation of HOX genes during differentiation, and activation of anterior 
281

282

283

284

285

286

287

288

289

290

291

292

293

294

295

296

297

298

299

300

301

HOX genes in hindbrain development during early embryogenesis, were enriched in the REAC database. A myogenesis pathway was also found.

ROBO family genes regulate axonal guidance and cell migration. $\mathrm{ROBO} 1$ and $\mathrm{ROBO} 2$ receptors regulate the proliferation and transition of primary to intermediate neuronal progenitors (Borrell et al., 2012), while the interaction of ROBO4 with SLIT3 is involved in the proliferation, motility and chemotaxis of endothelial cells, and accelerates the formation of blood vessels (Zhang et al., 2009). We found that the regulation of commissural axon pathfinding by SLIT, ROBO, netrin-1 signaling and pathways with signaling by ROBO receptors, semaphorin interactions, neurotransmitter release cycle were enriched. These results support that activation and inactivation of developmental signaling pathways initiate embryonic and organ development. Abnormalities in any link may cause deformities.

3

Epidemiological data confirmed that smoking by any parent or the presence of any household smoking increased the risk of clubfoot in Peru (Palma et al., 2013). Maternal diabetes also showed a significant association with clubfoot (Parker et al., 2009). In mice, maternal smoking or diabetes increased mitochondrial damage and oxidative stresses (Stangenberg et al., 2015). In addition, maternal diabetes also increased hypoxia-inducible factor $1 \alpha$ expression in utero (Moazzen et al., 2015). Robertson et al. confirmed that clubfoot was caused by an intrauterine enterovirus through allowing anterior horn cell lesions (Robertson and Corbett, 1997). The adverse in utero environment caused by the external or internal environment may increase 
302

303

304

305

306

307

308

309

310

311

312

313

314

315

316

317

318

oxidative stress and thus induce cell damage in utero. We found that the signaling pathways involved in the regulation of gene expression by hypoxia-inducible factor, reactive oxygen species detoxification, cell response to hypoxia, cell response to heat stress, cell response to stress, oxidative stress-induced senescence, cellular senescence, and cellular responses to external stimuli were enriched in the REAC database. In addition, these external stimuli activate the immune system. We also found that interleukin family signaling, MAP kinase activation, toll-like receptor family cascade, adaptive immune system, and innate immune system were enriched. These data indicate that abnormal changes in the immune system and cell response to external stimuli may play key roles in clubfoot.

In the enrichment analysis, we also found that several molecular transport pathways were enriched by enrichment analysis, and induced plasma lipoprotein assembly, remodeling, and clearance, iron uptake and transport, small molecules transport, binding and uptake of ligands by scavenger receptors, lysosome vesicle biogenesis, vesicle-mediated transport, trans-Golgi network vesicle budding, and membrane trafficking. Molecular transport is essential for material transport, signal transduction and neurotransmitter transporters and modulates the cell response to an external force (Hu and Papoian, 2013). Disorders induced by abnormal molecular transport are serious and even fatal for cells. Based on these results, we proposed that molecular transport abnormalities may play a large role in clubfoot. 
323

324

325

326

327

328

329

330

331

332

enrichment analyses, and induced regulation of IGF transport and uptake by IGFBPs, activation

of genes by ATF4 in response to endoplasmic reticulum stress, synthesis, secretion, and inactivation of GLP-1, metabolism of nitric oxide, activation and regulation of eNOS, metabolism of carbohydrates, and regulation of lipid metabolism by PPAR $\alpha$. A previous study indicated that lipid droplets and glycogen increased and the number of mitochondria decreased in chondrocytes from the biopsied iliac crest cartilage of joint contracture patients (Nogami et al., 1983). These data suggested that glucose metabolism, lipid metabolism and mitochondrial oxidative stress were associated with multiple joint contractures. In the present work, glucose metabolism regulated by IGF or GLP, lipid metabolism regulated by PPAR, and oxidative stress regulated by NOS were found in the REAC database. These data suggest that metabolic abnormalities may play a significant role in clubfoot.

All candidate papers were obtained from PubMed and Science Direct. Almost all of these differentially expressed proteins were carefully and strictly selected from clinical trials. Clubfoot is abnormal in both bone and muscle. Most of the samples are from bone, and few are from muscle, therefore selection bias cannot be avoided. Through strict screening criteria, candidate proteins from different tissues were adopted for subsequent bioinformatics analysis, and the selection bias was possibly minimized. Although the adjusted $\mathrm{p}$ value method was performed, there may be some false positives in using these candidate proteins for bioinformatics analysis because these proteins were not collected from the same investigation. Although we proposed that cell or immune responses to external stimuli, abnormal molecular transport and metabolism 
344 are new potential etiopathogenetic mechanisms of clubfoot, direct experimental evidence is

345 needed. We are carrying out preclinical and clinical studies to confirm these enrichment

346 pathways and proposed hypotheses.

\section{Conclusions}

348 In summary, a large number of signaling pathways were enriched using REAC, KEGG and WP

349 enrichment analyses by g:Profiler, NetworkAnalyst and WebGestalt. Among them, signal

transduction, disease, metabolism, gene expression (transcription), immune system,

developmental biology, cell cycle, and ECM were the top functions. GO enrichment analysis

also revealed pathways in embryo or organ development, and ECM proteins were dominant.

PPIs and GRNs analysis results indicated that extensive and complex interactions occur in these

proteins, enrichment pathways, and TF-miRNA coregulatory networks. Transcription factors

such as SOX9, CTNNB1, GLI3, FHL2, TGFBI and HOXD13, cooperated with hsa-miR-29a,

hsa-miR-101, hsa-miR-520d-5p, hsa-miR-29b and hsa-miR-568 and regulated these candidate

proteins. In addition to supporting the proposed hypotheses, such as ECM abnormalities, fetal

movement reduction, genetic abnormalities, muscle abnormalities, neurological abnormalities,

skeletal abnormalities, uterine compression and vascular abnormalities, we propose that cellular

or immune responses to external stimuli, and abnormal molecular transport or metabolism are new potential etiological mechanisms of clubfoot. 
365 No application.

366

367 Competing Interests

368 The authors declare no competing interests.

369

370

Author Contributions

Jing Ding and Wu Z conceived and designed the study. Cai G and Yang X performed enrichment analysis. Jin F, Cai G, Yang X and Chen T wrote and revised the paper. All authors read and approved the manuscript.

Data Availability

All data generated or analyzed during this study are in this published article (and its supplementary information files).

Figure Legends:

Figure 1. Inclusion criteria for abnormal protein candidates and the process of bioinformatics analysis.

Figure 2. Overall results of bioinformatics analyses with candidate proteins using g:Profiler and Reactome. (A) The significantly changed terms enriched by GO, KEGG, Reactome (REAC), 
385 Wikipathways (WP) and Human phenotype ontology (HP) databases. (B) The enrichment

386

387

388

389

390

391

392

393

394

395

396

397

398

399

400

401

402

403

404

405

Figure 3. Classification statistics of significantly enriched pathways by REAC shown in Figure

2B. Enrichment analysis methods are described in the Materials and Methods section. (A)

Distribution of the enrichment pathways. (B) High frequency molecules in all of the significant signaling pathways were mapped by Wordart software (https://wordart.com). The larger the word frequency was, the larger the font size. (C) The top 10 proteins involved in enrichment pathways and their proportions. (D) The top 10 signaling pathways. Four columns on the left are the results of the top 10 FDR, entities, reactions and interactors. The numbers are their ranks. The hit numbers for each pathway are shown in column 5.

Figure 4. Signaling pathway enrichment analysis by g:Profiler in the (A) REAC, (B) WP, (C) KEGG and (D) HP databases. Statistical results of signaling pathways from REAC (E) and HP (F). (G) Graphical illustration.

Figure 5. GO enrichment analysis by g:Profiler. (A) BP, (B) MF and (C) CC terms. (D) Graphical illustration. Statistical results from the GO BP (E), MF (F) and CC (G) enrichment analysis.

Figure 6. PPIs and GRNs analyses of these candidate protein-coding genes by NetworkAnalyst. 
406 Generic PPI (A) and the top 10 genes (B) involved in that PPI. TF-gene interactions (C) and the 407 top 10 genes (D)involved in these interactions. Genes are shown as pink circles, and transcription 408 factors are shown as blue squares. Gene-miRNA interactome (E) and the top 10 genes (F) 409 involved in these interactions. Genes are shown as pink circles and miRNAs are shown as blue 410 squares. TF-miRNA coregulatory interactions $(\mathrm{G})$ and the top 10 genes $(\mathrm{H})$ involved in these 411 interactions. Genes are circles. miRNAs are shown as blue diamonds. TFs are shown as green 412 diamonds. The distribution (I) and frequency $(\mathrm{J})$ of the top 10 genes in these four interaction 413 networks mentioned above are shown.

\section{Supplementary Materials}

Figure S1. Pathway enrichment analyses by NetworkAnalyst and WebGestalt. (A) KEGG

pathway analysis by NetworkAnalyst. (B) KEGG pathway analysis by WebGestalt. (C)

Reactome pathway analysis by NetworkAnalyst. (B) Reactome pathway analysis by WebGestalt.

Figure S2. GO enrichment analysis by NetworkAnalyst. (A) (D) GO: BP. (B) (E) GO: MF. (C)

(F) GO: CC.

422

\section{REFERENCES}

Alvarez CM, De Vera MA, Chhina H, Williams L, Durlacher K, Kaga S. 2009. The use of botulinum type A toxin in the treatment of idiopathic clubfoot: 5-year follow-up. J Pediatr Orthop 29(6):570-5. DOI 10.1097/bpo.0b013e3181b2b3d4.

Basit S and Khoshhal KI. 2018. Genetics of clubfoot; recent progress and future perspectives. 
428

429

430

431

432

433

434

435

436

437

438

439

440

441

442

443

444

445

446

447

448

449

450

Eur J Med Genet 61(2):107-113. DOI 10.1016/j.ejmg.2017.09.006.

Borrell V, Cárdenas A, Ciceri G, Galcerán J, Flames N, Pla R, Nóbrega-Pereira S, GarcíaFrigola C, Peregrín S, Zhao Z, Ma L, Tessier-Lavigne M, Marín O. 2012. Slit/Robo signaling modulates the proliferation of central nervous system progenitors. Neuron 76(2):338-52. DOI 10.1016/j.neuron.2012.08.003.

Breuer K, Foroushani AK, Laird MR, Chen C, Sribnaia A, Lo R, Winsor GL, Hancock RE, Brinkman FS, Lynn DJ. 2013. InnateDB: systems biology of innate immunity and beyond-recent updates and continuing curation. Nucleic Acids Res 41(Database issue):D1228-33. DOI 10.1093/nar/gks1147.

Cao D, Jin C, Ren M, Lin C, Zhang X, Zhao N. 2009. The expression of Gli3, regulated by HOXD13, may play a role in idiopathic congenital talipes equinovarus. BMC Musculoskelet Disord 2009; 10:142. DOI 10.1186/1471-2474-10-142.

Chesney D, Barker S, Maffulli N. 2007. Subjective and objective outcome in congenital clubfoot; a comparative study of 204 children. BMC Musculoskelet Disord 8:53. DOI 10.1186/1471-2474-8-53.

Chou CH, Shrestha S, Yang CD, Chang NW, Lin YL, Liao KW, Huang WC, Sun TH, Tu SJ, Lee WH, Chiew MY, Tai CS, Wei TY, Tsai TR, Huang HT, Wang CY, Wu HY, Ho SY, Chen PR, Chuang CH, Hsieh PJ, Wu YS, Chen WL, Li MJ, Wu YC, Huang XY, Ng FL, Buddhakosai W, Huang PC, Lan KC, Huang CY, Weng SL, Cheng YN, Liang C, Hsu WL, Huang HD. 2018. miRTarBase update 2018: a resource for experimentally validated microRNA-target interactions. Nucleic Acids Res 46(D1):D296-D302. DOI 10.1093/nar/gkx1067.

Eckhardt A, Novotny T, Doubkova M, Hronkova L, Vajner L, Pataridis S, Hadraba D, 
451

452

453

454

455

456

457

458

459

460

461

462

463

464

465

466

467

468

469

470

471

472

473

Kulhava L, Plencner M, Knitlova J, Liskova J, Uhlik J, Zaloudikova M, Vondrasek D, Mikšík I, Ošt'ádal M. 2019. Novel contribution to clubfoot pathogenesis: The possible role of extracellular matrix proteins. J Orthop Res 2019; 37(3):769-78. DOI 10.1002/jor.24211.

Esteban-Martínez L, Sierra-Filardi E, Boya P. 2017. Mitophagy, metabolism, and cell fate. Mol Cell Oncol 4(5):e1353854. DOI 10.1080/23723556.2017.1353854.

Ester AR, Weymouth KS, Burt A, Wise CA, Scott A, Gurnett CA, Dobbs MB, Blanton SH, Hecht JT. 2010. Altered transmission of HOX and apoptotic SNPs identify a potential common pathway for clubfoot. Am J Med Genet A 149A(12):2745-52. DOI 10.1002/ajmg.a.33130.

Fabregat A, Sidiropoulos K, Garapati P, Gillespie M, Hausmann K, Haw R, Jassal B, Jupe S, Korninger F, McKay S, Matthews L, May B, Milacic M, Rothfels K, Shamovsky V, Webber M, Weiser J, Williams M, Wu G, Stein L, Hermjakob H, D'Eustachio P. 2016. The Reactome pathway Knowledgebase. Nucleic Acids Res 44(D1):D481-7. DOI 10.1093/nar/gkt1102.

Hecht JT, Ester A, Scott A, Wise CA, Iovannisci DM, Lammer EJ, Langlois PH, Blanton SH. 2007. NAT2 variation and idiopathic talipes equinovarus (clubfoot). Am J Med Genet A 143A(19):2285-91. DOI 10.1002/ajmg.a.31927.

Herceg MB, Weiner DS, Agamanolis DP, Hawk D. 2006. Histologic and histochemical analysis of muscle specimens in idiopathic talipes equinovarus. J Pediatr Orthop 26(1):91-3. DOI 10.1097/01.bpo.0000188994.90931.e8.

Hester TW, Parkinson LC, Robson J, Misra S, Sangha H, Martin JE. Hester TW1, Parkinson LC, Robson J, Misra S, Sangha H, Martin JE. 2009. A hypothesis and model of reduced fetal movement as a common pathogenetic mechanism in clubfoot. Med 
474

475

476

477

478

479

480

481

482

483

484

485

486

487

488

489

490

491

492

493

494

495

496

Hypotheses 73(6):986-8. DOI 10.1016/j.mehy.2009.04.056.

Howren AM, Jamieson DH, Alvarez CM. 2015. Early ultrasonographic evaluation of idiopathic clubfeet treated with manipulations, casts, and Botox $\left({ }^{\circledR}\right)$ : a double-blind randomized control trial. J Child Orthop 9(1):85-91. DOI 10.1007/s11832-015-0633-4.

Hu L and Papoian GA. 2013. Molecular transport modulates the adaptive response of branched actin networks to an external force. J Phys Chem B 117(42):13388-96. DOI 10.1021/jp405179e.

Li C, Nguyen Q, Cole WG, Alman BA. 2001. Potential treatment for clubfeet based on growth factor blockade. J Pediatr Orthop 21(3):372-7. DOI 10.1097/01241398-200105000-00021.

Liu ZP, Wu C, Miao H, Wu H. 2015. RegNetwork: an integrated database of transcriptional and post-transcriptional regulatory networks in human and mouse. Database (Oxford) pii: bav095. DOI 10.1093/database/bav095.

Lovell ME, Morcuende JA. 2007. Neuromuscular disease as the cause of late clubfoot relapses: report of 4 cases. Iowa Orthop J 27:82-4.

Miedzybrodzka Z. 2003. Congenital talipes equinovarus (clubfoot): a disorder of the foot but not the hand. J Anat. 202(1):37-42. DOI 10.1046/j.1469-7580.2003.00147.x.

Miller NH, Carry PM, Mark BJ, Engelman GH, Georgopoulos G, Graham S, Dobbs MB. 2016. Does Strict Adherence to the Ponseti Method Improve Isolated Clubfoot Treatment Outcomes? A Two-institution Review. Clin Orthop Relat Res 474(1):237-43. DOI 10.1007/s11999-015-4559-4.

Moazzen H, Lu X, Liu M, Feng Q. 2015. Pregestational diabetes induces fetal coronary artery malformation via reactive oxygen species signaling. Diabetes 64(4):1431-43. DOI 10.2337/db14-0190. 
497

498

499

500

501

502

503

504

505

506

507

508

509

510

511

512

513

514

515

516

517

518

519

Nogami H, Ogasawara N, Kasai T, Oki T, Murachi S. 1983. Lipid storage myopathy associated with scoliosis and multiple joint contractures. Acta Neuropathol 1983; 61(34):305-10. DOI 10.1007/bf00692002.

Ohuchi H, Noji S. 1999. Fibroblast-growth-factor-induced additional limbs in the study of initiation of limb formation, limb identity, myogenesis, and innervation. Cell Tissue Res 296(1):45-56. DOI 10.1007/s004410051265.

Ošt'ádal M, Eckhardt A, Herget J, Mikšík I, Dungl P, Chomiak J, Frydrychová M, Burian M. 2015. Proteomic analysis of the extracellular matrix in idiopathic pes equinovarus. Mol Cell Biochem 401(1-2):133-9. DOI 10.1007/s11010-014-2300-3.

Palma M1, Cook T, Segura J, Pecho A, Morcuende JA. 2013. Descriptive epidemiology of clubfoot in Peru: a clinic-based study. Iowa Orthop J 2013; 33:167-71.

Parker SE, Mai CT, Strickland MJ, Olney RS, Rickard R, Marengo L, Wang Y, Hashmi SS, Meyer RE; National Birth Defects Prevention Network. 2009. Multistate study of the epidemiology of clubfoot. Birth Defects Res A Clin Mol Teratol 85(11):897-904. DOI 10.1002/bdra.20625.

Pavone V, Chisari E, Vescio A, Lucenti L, Sessa G, Testa G. 2018. The etiology of idiopathic congenital talipes equinovarus: a systematic review. J Orthop Surg Res 2018; 13(1):206. doi: 10.1186/s13018-018-0913-z. DOI 10.1186/s13018-018-0913-z.

Poon R, Li C, Alman BA. 2009. Beta-catenin mediates soft tissue contracture in clubfoot. Clin Orthop Relat Res467(5):1180-5. DOI 10.1007/s11999-008-0692-7.

Robertson WW Jr, Corbett D. 1997. Congenital clubfoot. Month of conception. Clin Orthop Relat Res (338):14-8. DOI 10.1097/00003086-199705000-00004.

Shrimpton AE, Levinsohn EM, Yozawitz JM, Packard DS Jr, Cady RB, Middleton FA, 
520

521

522

523

524

525

526

527

528

529

530

531

532

533

534

535

536

537

538

539

540

541

542

Persico AM, Hootnick DR. 2004. A HOX gene mutation in a family with isolated congenital vertical talus and Charcot-Marie-Tooth disease. Am J Hum Genet 75(1):92-6. DOI 10.1086/422015.

Shyy W, Dietz F, Dobbs MB, Sheffield VC, Morcuende JA. 2009. Evaluation of CAND2 and WNT7a as candidate genes for congenital idiopathic clubfoot. Clin Orthop Relat Res 467(5):1201-5. DOI 10.1007/s11999-008-0701-x.

Smith PA, Kuo KN, Graf AN, Krzak J, Flanagan A, Hassani S, Caudill AK, Dietz FR, Morcuende J, Harris GF. 2014. Long-term results of comprehensive clubfoot release versus the Ponseti method: which is better? Clin Orthop Relat Res 472(4):1281-90. DOI 10.1007/s11999-013-3386-8.

Sodre H, Bruschini S, Mestriner LA, Miranda F Jr, Levinsohn EM, Packard DS Jr, Crider RJ Jr, Schwartz R, Hootnick DR. 1990. Arterial abnormalities in talipes equinovarus as assessed by angiography and the Doppler technique. J Pediatr Orthop 10(1):101-4. DOI 10.1097/01241398-199010010-00020.

Stangenberg S, Nguyen LT, Chen H, Al-Odat I, Killingsworth MC, Gosnell ME, Anwer AG, Goldys EM, Pollock CA, Saad S. 2015. Oxidative stress, mitochondrial perturbations and fetal programming of renal disease induced by maternal smoking. Int J Biochem Cell Biol 2015; 64:81-90. DOI 10.1016/j.biocel.2015.03.017.

Thacker MM, Scher DM, Sala DA, van Bosse HJ, Feldman DS, Lehman WB. 2005. Use of the foot abduction orthosis following Ponseti casts: is it essential? J Pediatr Orthop 25(2):225-8. DOI 10.1097/01.bpo.0000150814.56790.f9.

Vlachos IS, Paraskevopoulou MD, Karagkouni D, Georgakilas G, Vergoulis T, Kanellos I, Anastasopoulos IL, Maniou S, Karathanou K, Kalfakakou D, Fevgas A, Dalamagas T, 
543

544

545

546

547

548

549

550

551

552

553

554

555

556

557

558

559

560

561

562

563

564

565

Hatzigeorgiou AG. 2015. DIANA-TarBase v7.0: indexing more than half a million experimentally supported miRNA:mRNA interactions. Nucl. Acids Res 43(Database issue):D153-9. DOI 10.1093/nar/gku1215.

Wang H, Barisic I, Loane M, Addor MC, Bailey LM, Gatt M, Klungsoyr K, Mokoroa O, Nelen V, Neville AJ, O'Mahony M, Pierini A, Rissmann A, Verellen-Dumoulin C, de Walle HEK, Wiesel A, Wisniewska K, de Jong-van den Berg LTW, Dolk H, Khoshnood B, Garne E. 2019. Congenital clubfoot in Europe: A population-based study. Am J Med Genet A 179(4):595-601. DOI 10.1002/ajmg.a.61067.

Wang J, Vasaikar S, Shi Z, Greer M, Zhang B. 2017. WebGestalt 2017: a more comprehensive, powerful, flexible and interactive gene set enrichment analysis toolkit. Nucleic Acids Res 45(W1):W130-W137. DOI 10.1093/nar/gkx356.

Wang LL, Fu WN, Li-Ling J, Li ZG, Li LY, Sun KL. 2008. HOXD13 may play a role in idiopathic congenital clubfoot by regulating the expression of FHL1. Cytogenet Genome Res 121(3-4):189-95. DOI 10.1159/000138884.

Wang S, Sun H, Ma J, Zang C, Wang C, Wang J, Tang Q, Meyer CA, Zhang Y, Liu XS. 2013. Target analysis by integration of transcriptome and ChIP-seq data with BETA. Nat Protoc8(12):2502-15. DOI 10.1038/nprot.2013.150.

Wang Z, Yan N, Liu L, Cao D, Gao M, Lin C, Jin C. 2013. SOX9 overexpression plays a potential role in idiopathic congenital talipes equinovarus. Mol Med Rep 7(3):821-5. DOI $10.3892 / \mathrm{mmr} .2012 .1245$.

Weymouth KS, Blanton SH, Powell T, Patel CV, Savill SA, Hecht JT. 2016. Functional Assessment of Clubfoot Associated HOXA9, TPM1, and TPM2 Variants Suggests a Potential Gene Regulation Mechanism. Clin Orthop Relat Res 474(7):1726-35. DOI 
$566 \quad 10.1007 / \mathrm{s} 11999-016-4788-1$.

567 Zhang B, Dietrich UM, Geng JG, Bicknell R, Esko JD, Wang L. 2009. Repulsive axon

568 guidance molecule Slit3 is a novel angiogenic factor. Blood 114(19):4300-9. DOI

$569 \quad 10.1182 /$ blood-2008-12-193326.

570 Zhang Z, Kong Z, Zhu M, Lu W, Ni L, Bai Y, Lou Y. 2016. Whole genome sequencing

571 identifies ANXA3 and MTHFR mutations in a large family with an unknown equinus

572 deformity associated genetic disorder. Mol Biol Rep 43:1147-55. DOI 10.1007/s11033-016-

$573 \quad 4047-2$.

574 Zionts LE, Zhao G, Hitchcock K, Maewal J, Ebramzadeh E. 2010. Has the rate of extensive

575 surgery to treat idiopathic clubfoot declined in the United States? J Bone Joint Surg Am

576 92(4):882-9. DOI 10.2106/JBJS.I.00819. 
Figure 1

Figure 1. Inclusion criteria for abnormal protein candidates and the process of bioinformatics analysis. 


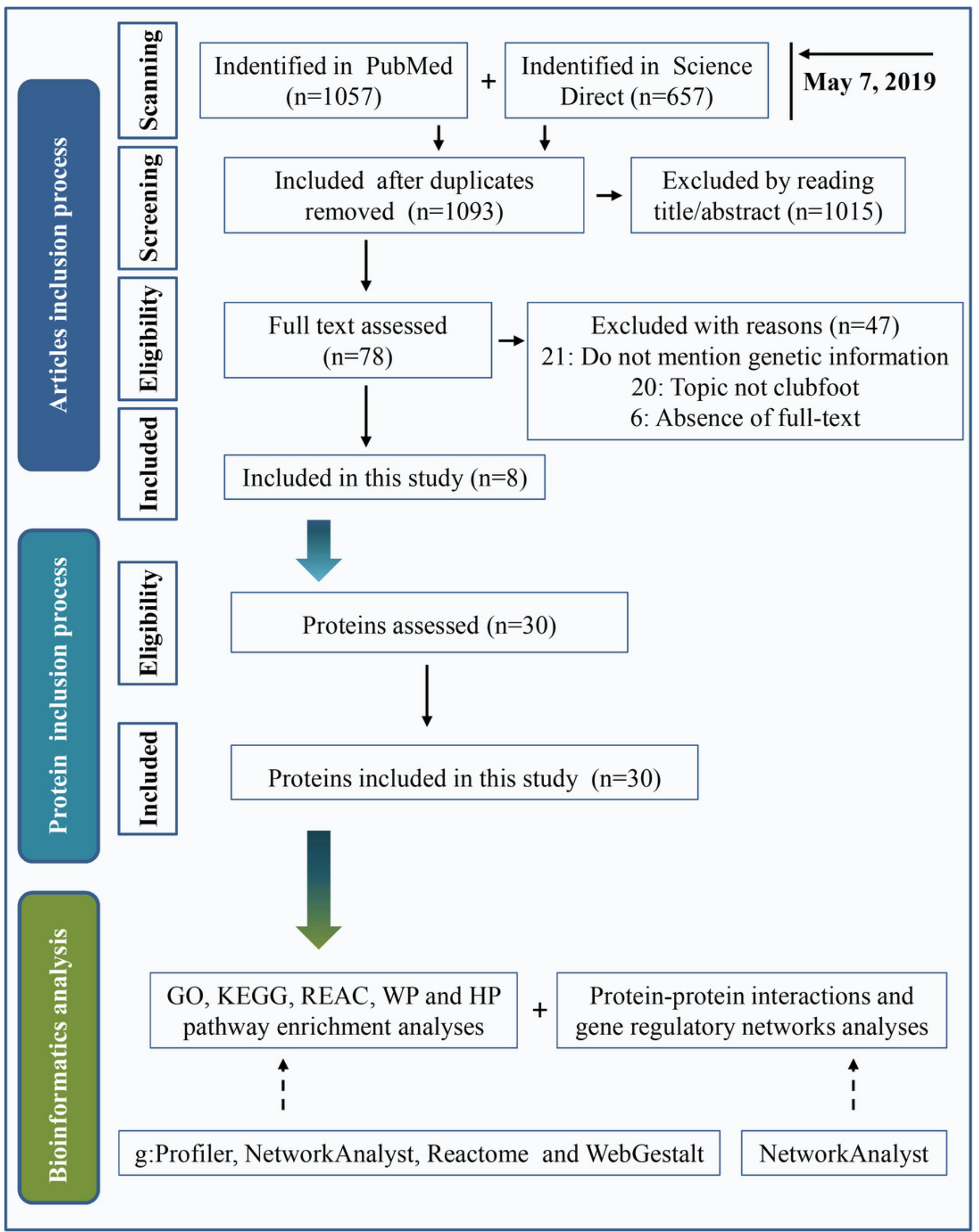


Figure 2

Figure 2. Overall results of bioinformatics analyses with candidate proteins using g:Profiler and Reactome.

(A) The significantly changed terms enriched by GO, KEGG, Reactome (REAC), Wikipathways (WP) and Human phenotype ontology (HP) databases. (B) The enrichment pathways and their interactions enriched by REAC.

A

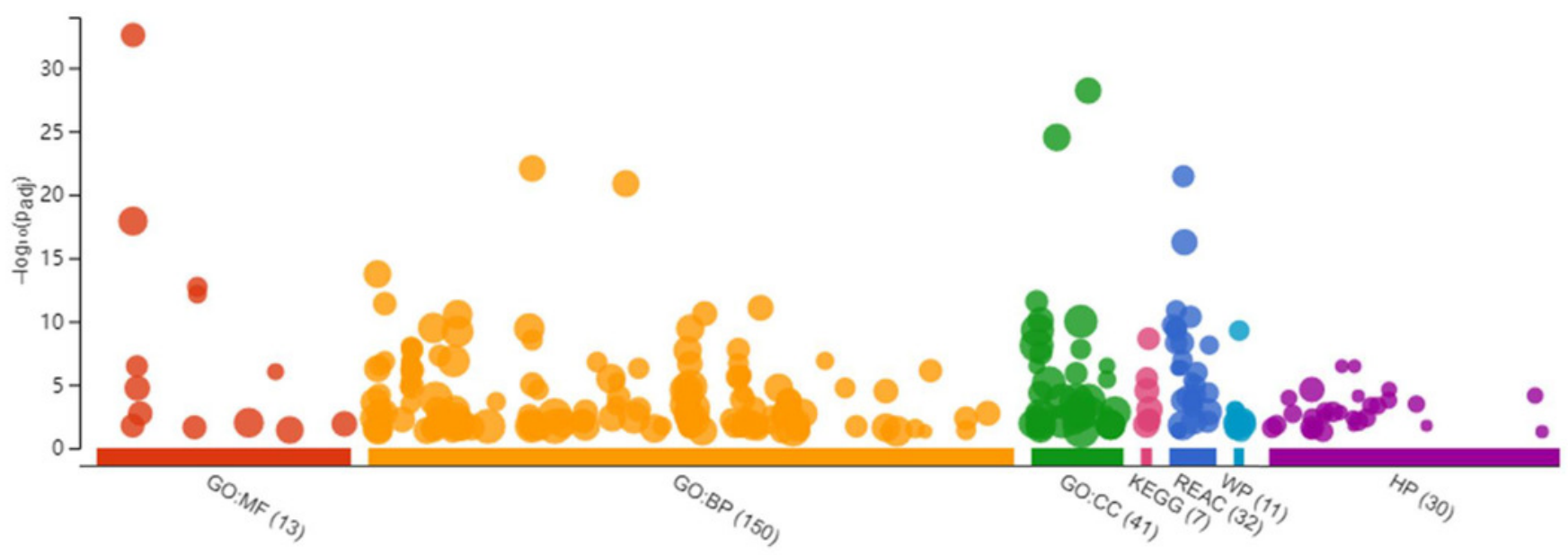

B

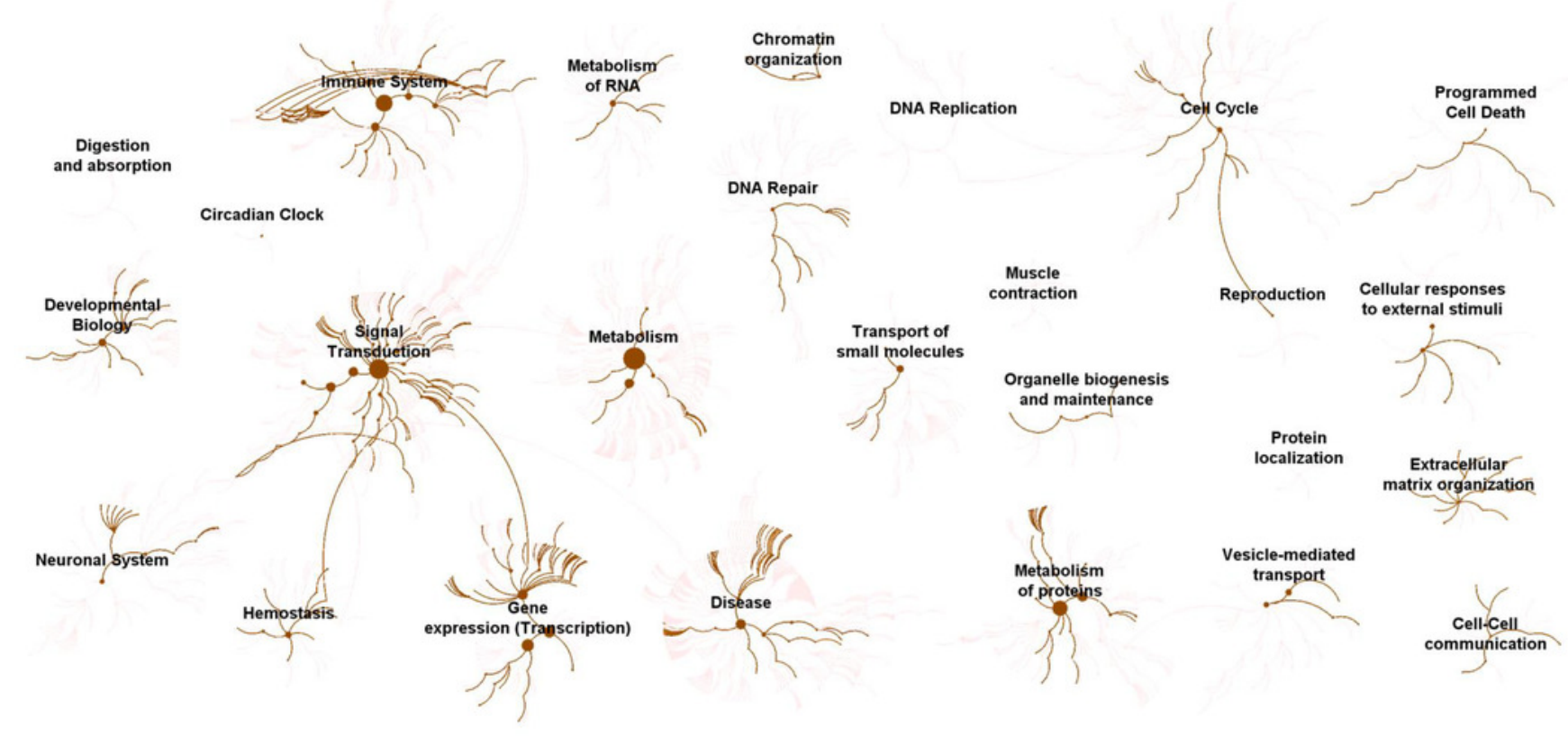




\section{Figure 3}

Figure 3. Classification statistics of significantly enriched pathways by REAC shown in Figure 2B.

Enrichment analysis methods are described in the Materials and Methods section. (A)

Distribution of the enrichment pathways. (B) High frequency molecules in all of the significant signaling pathways were mapped by Wordart software (https://wordart.com). The larger the word frequency was, the larger the font size. (C) The top 10 proteins involved in enrichment pathways and their proportions. (D) The top 10 signaling pathways. Four columns on the left are the results of the top 10 FDR, entities, reactions and interactors. The numbers are their ranks. The hit numbers for each pathway are shown in column 5 . 
A

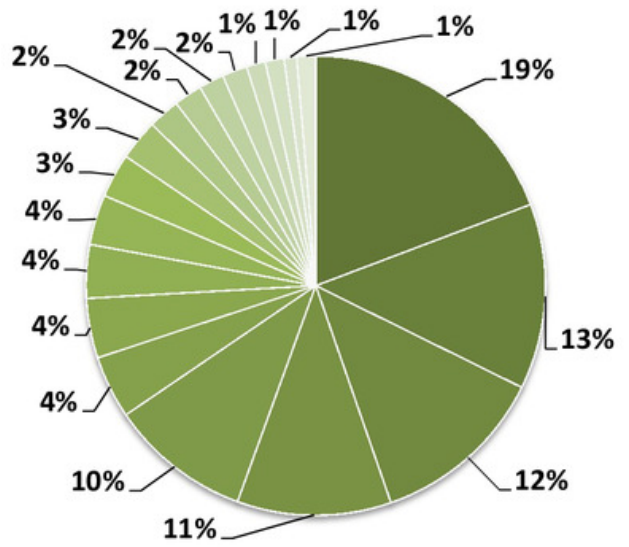

- Signal Transduction

- Disease

- Metabolism

- Gene expression (Transcription)

- Immune System

- Developmental Biology

= Cell Cycle

- Extracellular matrix organization

= Hemostasis

\author{
= DNA Repair \\ = Programmed Cell Death \\ = Cellular responses to external stimuli \\ = Cell-Cell communication \\ = Transport of small molecules \\ - Organelle biogenesis and maintenance \\ = Vesicle-mediated transport \\ Chromatin organization \\ Others
}

B

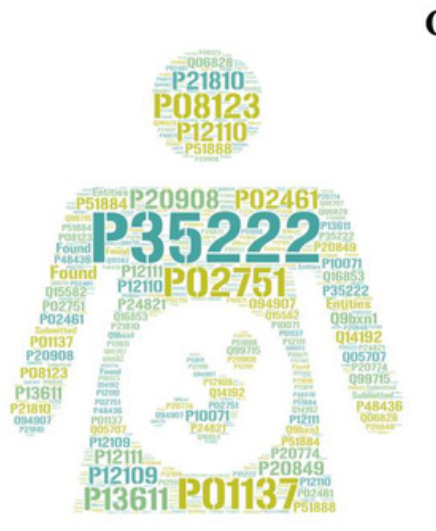

C

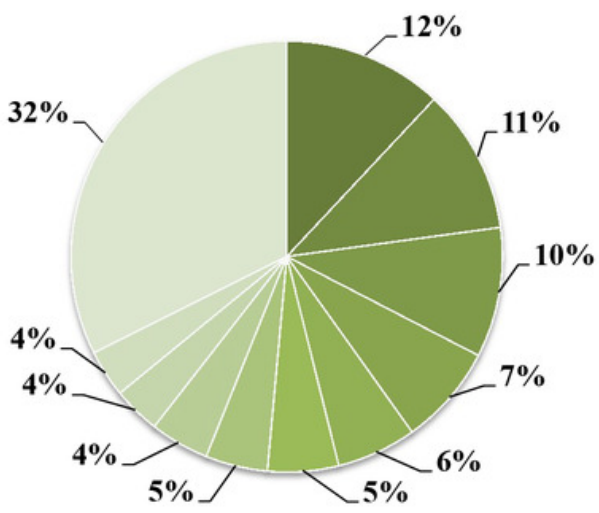

- P35222 Catenin beta-1

- P01137 TGF beta-1

- P02751 Fibronectin

- P08123 Collagen alpha-2(I) chain

= P02461 Collagen alpha-1(III) chain

=P13611 Versican

= P20908 Collagen alpha-1(V) chain

- P21810 Biglycan

- P12110 Collagen alpha-2(VI) chain

P12109 Collagen alpha-1(VI) chain

Others

D

\begin{tabular}{|c|c|c|c|c||l|l|l|}
\multicolumn{2}{|c|}{} & \multicolumn{2}{l|}{ Type } \\
\hline
\end{tabular}


Figure 4

Figure 4. Signaling pathway enrichment analysis by g:Profiler in the (A) REAC, (B) WP, (C) KEGG and (D) HP databases.

Signaling pathway enrichment analysis by g:Profiler in the (A) REAC, (B) WP, (C) KEGG and (D) HP databases. Statistical results of signaling pathways from REAC (E) and HP (F). (G) Graphical illustration.

A

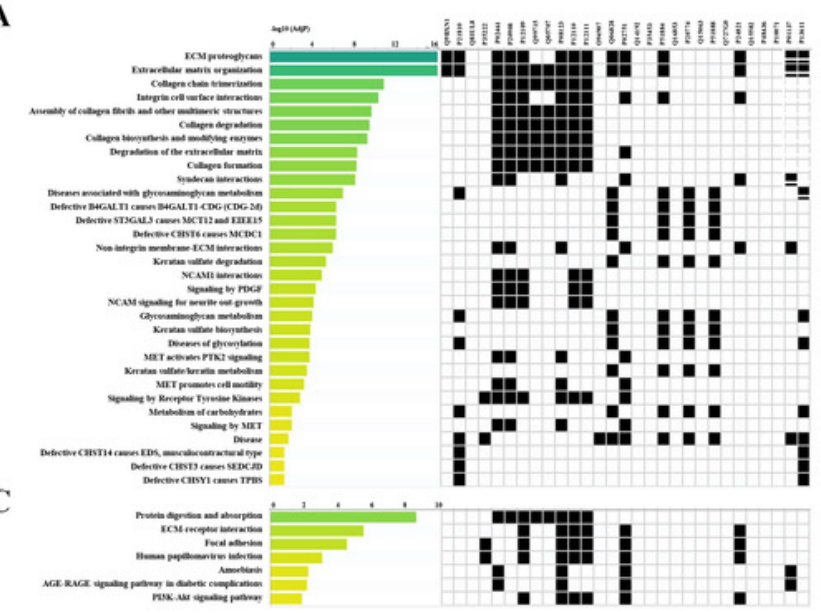

E

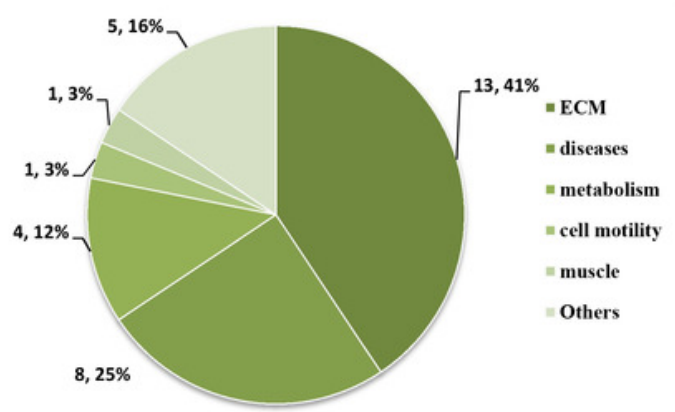

F
B
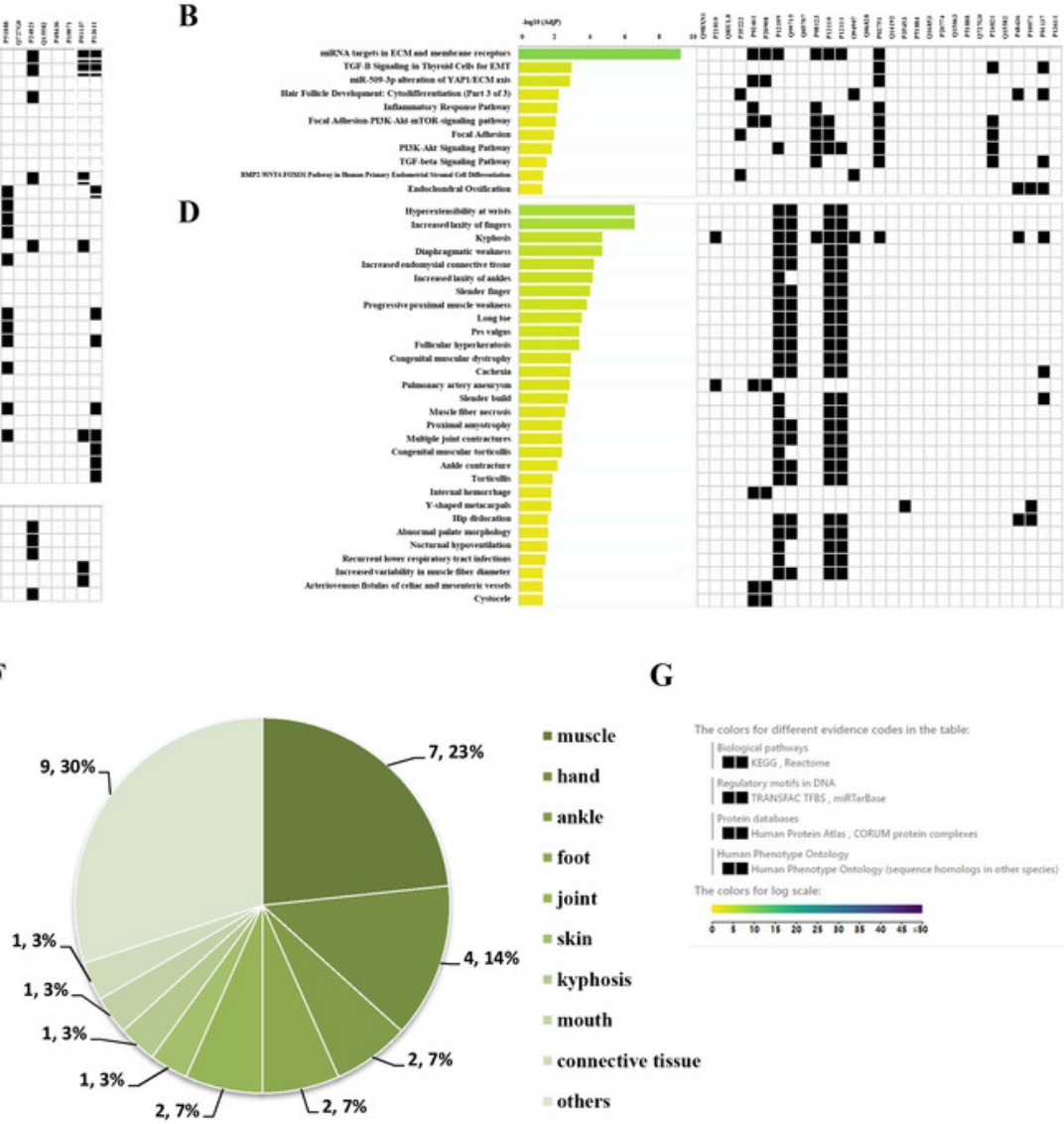

G

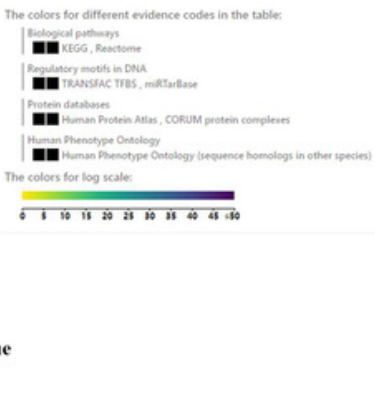




\section{Figure 5}

Figure 5. GO enrichment analysis by g:Profiler. (A) BP, (B) MF and (C) CC terms.

GO enrichment analysis by g:Profiler. (A) BP, (B) MF and (C) CC terms. (D) Graphical illustration. Statistical results from the GO BP (E), MF (F) and CC (G) enrichment analysis. 
A

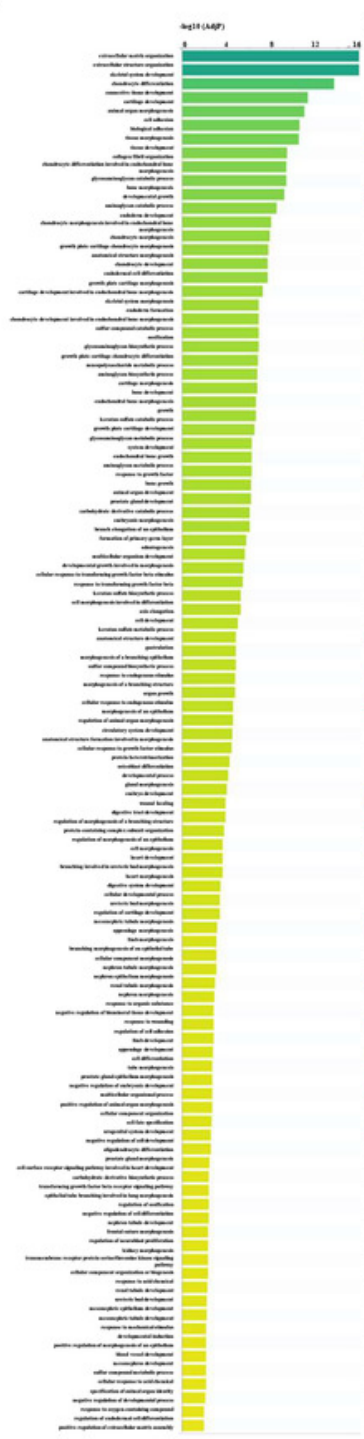

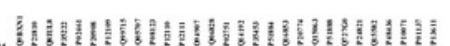

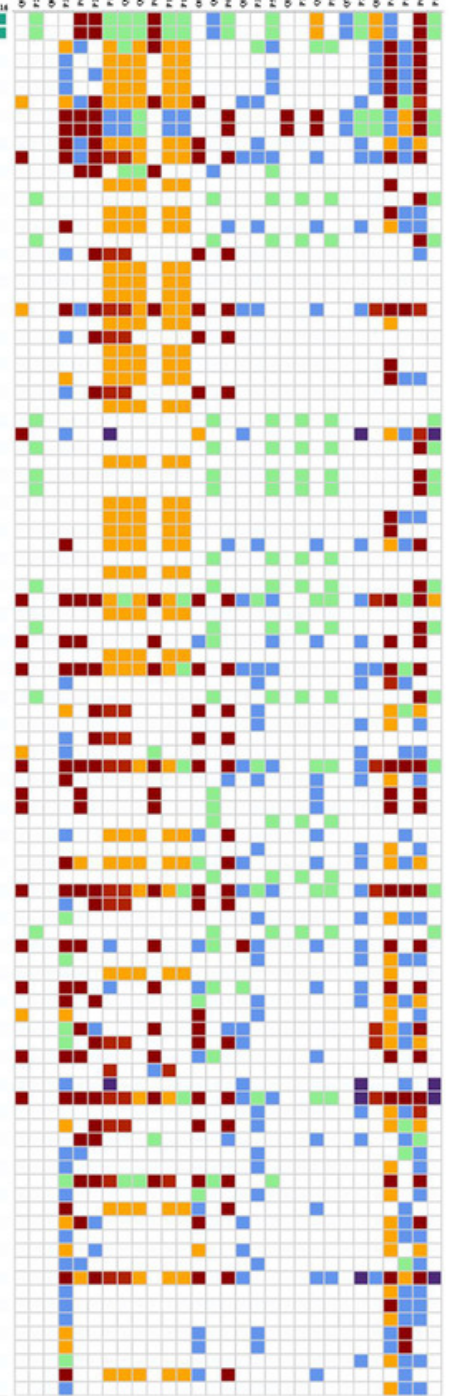

F
B

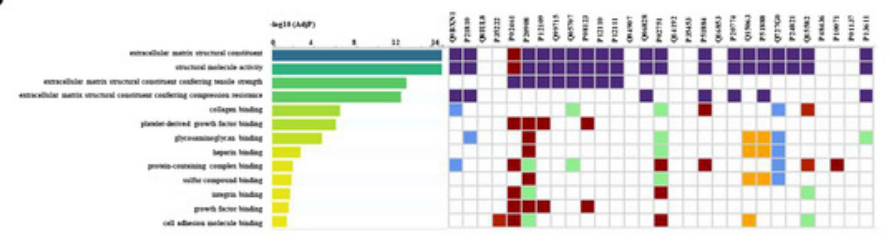

C

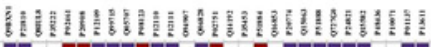

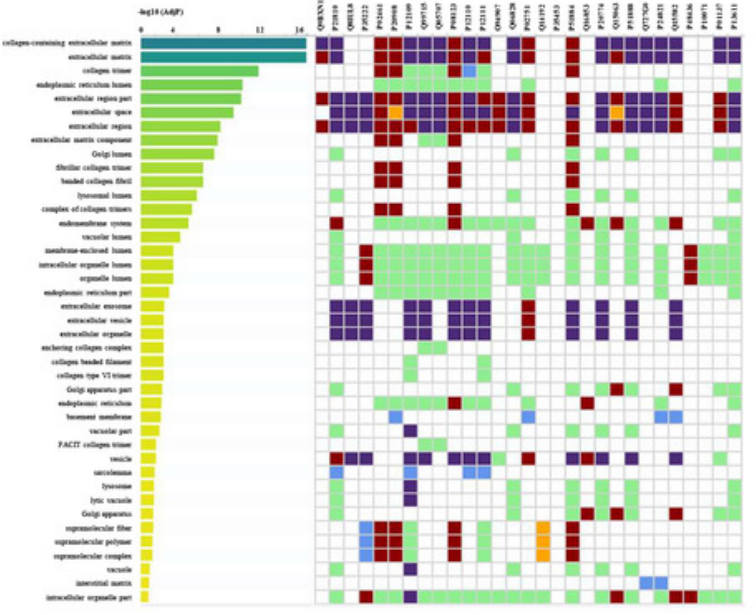

D

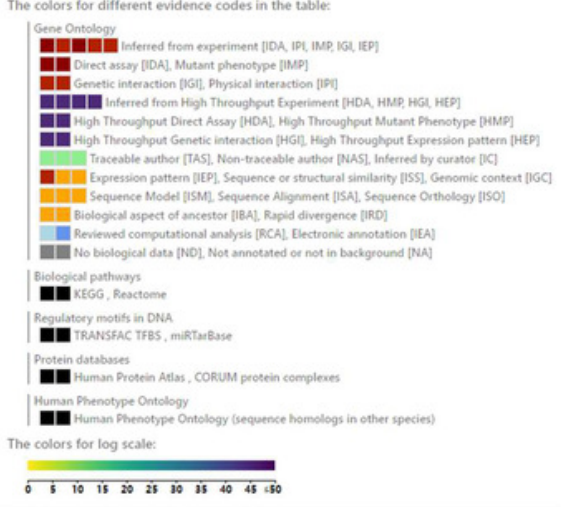

G

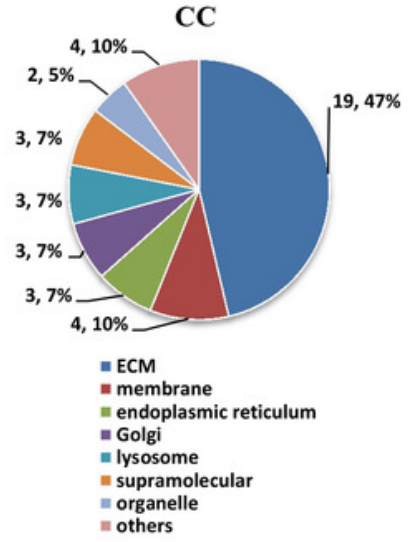




\section{Figure 6}

Figure 6. PPIs and GRNs analyses of these candidate protein-coding genes by NetworkAnalyst.

Generic PPI (A) and the top 10 genes (B) involved in that PPI. TF-gene interactions (C) and the top 10 genes (D)involved in these interactions. Genes are shown as pink circles, and transcription factors are shown as blue squares. Gene-miRNA interactome (E) and the top 10 genes $(F)$ involved in these interactions. Genes are shown as pink circles and miRNAs are shown as blue squares. TF-miRNA coregulatory interactions $(G)$ and the top 10 genes $(H)$ involved in these interactions. Genes are circles. miRNAs are shown as blue diamonds. TFs are shown as green diamonds. The distribution (I) and frequency $(\mathrm{J})$ of the top 10 genes in these four interaction networks mentioned above are shown.

A
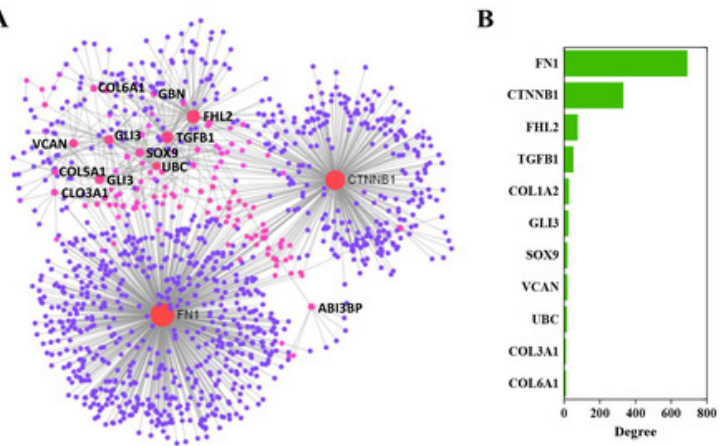

C
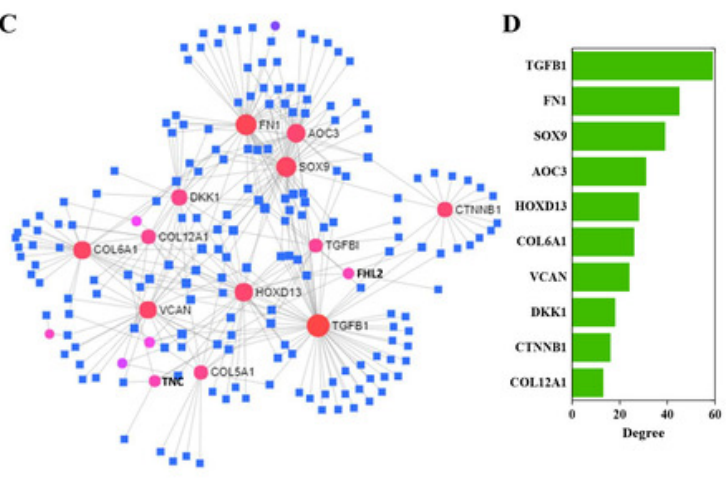

$\mathbf{E}$
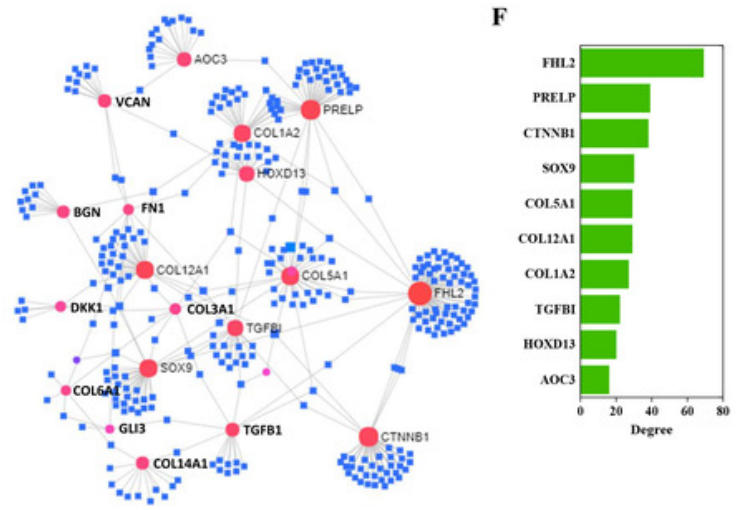

G

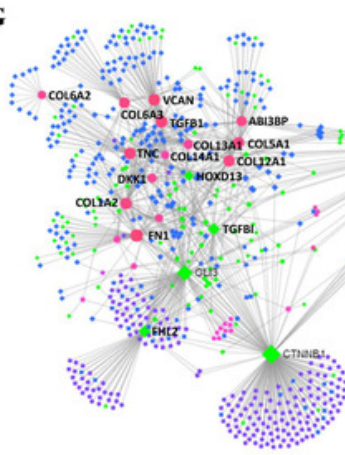

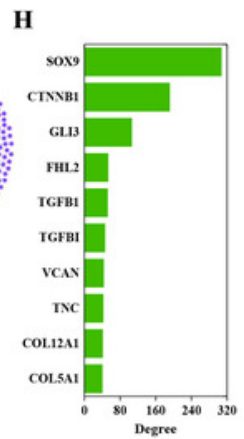

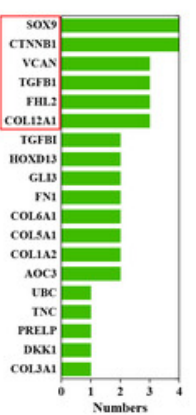

